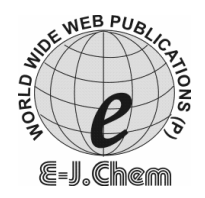

http://www.e-journals.net
ISSN: 0973-4945; CODEN ECJHAO

E-Journal of Chemistry 2009, 6(1), 223-230

\title{
Rapid and Sensitive Method for Quantitative Determination of Lopinavir and Ritonavir in Human Plasma by Liquid Chromatography- Tandem Mass Specrtometry
}

\author{
G. A. TEMGHARE*, S. S. SHETYE and S. S. JOSHI \\ K.J. Somaiya College of Science and Commerce, \\ Vidyavihar (East), Mumbai-400 077, India. \\ gayatrit23@rediffmail.com
}

Received 11 March 2008; Revised 14 May 2008; Accepted 5 June 2008

\begin{abstract}
A rapid and sensitive liquid chromatography-mass spectrometric (LCMS-MS) method for the simultaneous determination of lopinavir and ritonavir in human plasma using abacavir as internal standard has been developed and validated. Sample preparation of plasma involved solid phase extraction. Detection was performed using an Applied Biosystems Sciex API 2000 Mass spectrometer. The assay of lopinavir and ritonavir was linear over the range of $50 \mathrm{ng} \mathrm{mL}^{-1}$ to $20000 \mathrm{ng} \mathrm{mL}^{-1}$ and $20 \mathrm{ng} \mathrm{mL}^{-1}$ to $3000 \mathrm{ng} \mathrm{mL}^{-1}$ respectively with a precision of $<15 \%$ and accuracy in the range of $85-115 \%$. The limit of quantification in plasma for lopinavir and ritonavir was $50 \mathrm{ng} \mathrm{mL}^{-1}$ and $20 \mathrm{ng} \mathrm{mL}^{-1}$ respectively. The described method has the advantage of being rapid and easy and it could be applied in therapeutic monitoring of these drugs in human plasma.
\end{abstract}

Keywords: Human immunodeficiency virus (HIV)-1, Lopinavir , Ritonavir, LC-MS-MS

\section{Introduction}

Lopinavir is an inhibitor of the HIV protease. Ritonavir inhibits the CYP3A-mediated metabolism of lopinavir, thereby providing increased plasma levels of lopinavir ${ }^{1-6}$.

Lopinavir is chemically designated as [1S-[1R*, ( $\left.\left.\left.\mathrm{R}^{*}\right), 3 \mathrm{R}^{*}, 4 \mathrm{R} *\right]\right]-N-[4-[[(2,6-$ dimethylphenoxy) acetyl] amino]-3-hydroxy-5-phenyl-1- (phenylmethyl) pentyl] tetra 
hydro-alpha- (1-methylethyl)-2-oxo-1 $(2 \mathrm{H})$-pyrimidineacetamide. Its molecular formula is $\mathrm{C}_{37} \mathrm{H}_{48} \mathrm{~N}_{4} \mathrm{O}_{5}$, and its molecular weight is $628.80^{1}$. Ritonavir is chemically designated as 10 Hydroxy-2- methyl-5-(1-methylethyl)-4-thiazolyl]-3,6-dioxo-8,11-bis(phenylmethyl)2,4,7,12-tetraazatridecan-13-oic acid, 5-thiazolylmethyl ester, [5S$\left(5 \mathrm{R}^{*}, 8 \mathrm{R}^{*}, 10 \mathrm{R}^{*}, 11 \mathrm{R}^{*}\right)$ ]. Its molecular formula is $\mathrm{C}_{37} \mathrm{H}_{48} \mathrm{~N}_{6} \mathrm{O}_{5} \mathrm{~S}_{2}$ and its molecular weight $^{1,3}$ is 720.95 . The present paper deals with a biological assay of lopinavir and ritonavir simultaneously. Benefits of this method are improved sensitivity and recovery, which are mainly due to instrumental advances. The present LC-MS-MS method is well suited for studies generating large number of samples. In addition, much improved sensitivity was achieved with lower limit of quantification (LLOQ) of 50.0ng $\mathrm{mL}^{-1}$ for lopinavir and $20.0 \mathrm{ng} \mathrm{mL} \mathrm{L}^{-1}$ for ritonavir. Recoveries were about $80-90 \%$ for lopinavir and ritonavir.

\section{Experimental}

\section{Chemicals and reagents}

Working standard of lopinavir and ritonavir and abacavir were obtained from Cipla. Methanol and acetonitrile of HPLC grade and all other chemicals used were of analytical grade.

\section{Working standard preparation}

Stock solutions $\left(1000 \mu \mathrm{g} \mathrm{mL} \mathrm{m}^{-1}\right)$ of lopinavir, ritonavir and abacavir were prepared in methanol. Working solutions with different concentrations were prepared by dilution of stock with diluent (methanol: water 50: 50). Working solution for internal standard was also prepared in same diluent.

\section{Sample extraction}

Plasma samples to be processed were thawed at room temperature. Strata-X $33 \mu \mathrm{m}$ Polymeric Reversed Phase $(30 \mathrm{mg} / 1 \mathrm{~mL})$ cartridges were conditioned by passing through them $1 \mathrm{~mL}$ of methanol followed by $1 \mathrm{~mL}$ of water. To prepare samples for loading, $200 \mu \mathrm{L}$ plasma was mixed with $50 \mu \mathrm{L}$ of internal standard (approximately $2.000 \mu \mathrm{g} \mathrm{mL} \mathrm{m}^{-1}$ ). Sample was vortexed to mix, centrifuged for $5 \mathrm{~min}$ at $15000 \mathrm{rpm}$ and loaded on cartridge. Samples were washed with $2 \mathrm{~mL}$ water. Analyte and internal standard were eluted from the cartridges using $2000 \mu \mathrm{L}$ of mobile phase. $2 \mu \mathrm{L}$ of sample was injected onto LC-MS/MS.

\section{Instrumentation and chromatographic conditions}

The HPLC system (shimadzu) consist of an isocratic pump, an auto sampler and a Hypersil Hypurity $\mathrm{C}_{18}$ column $(50 \times 4.6 \mathrm{~mm}$, id $5 \mu)$. The mobile phase was prepared by mixing $2 \%$ formic acid with acetonitrile in the ratio of 20:80(v/v). Chromatography was performed at ambient temperature with a flow rate of $0.4 \mathrm{~mL} \mathrm{~min}^{-1}$. Detection was performed by an Applied Biosystems Sciex API 2000 Mass Spectrometer using atmospheric turbo ion spray for ion production. API was performed in the positive ion mode. The LC-MS-MS detector was operated at unit resolution in the multiple reactionmonitoring (MRM) mode. The transitions of the protonated molecular ions of lopinavir at $m / z 629.5 \rightarrow 183.3$, ritonavir at $m / z \quad 721.4 \rightarrow 296.3$ and abacavir at $m / z 287.2 \rightarrow 191.2$. Product ion mass spectra of lopinavir and ritonavir are shown in Figure 1 and 2 respectively. 
+MS2 (629.50) CE (30): 10 MCA scans from Sample 7 (Lopinavir msms P0S Full Scan) of Spectra.wiff(Turbo Spray)

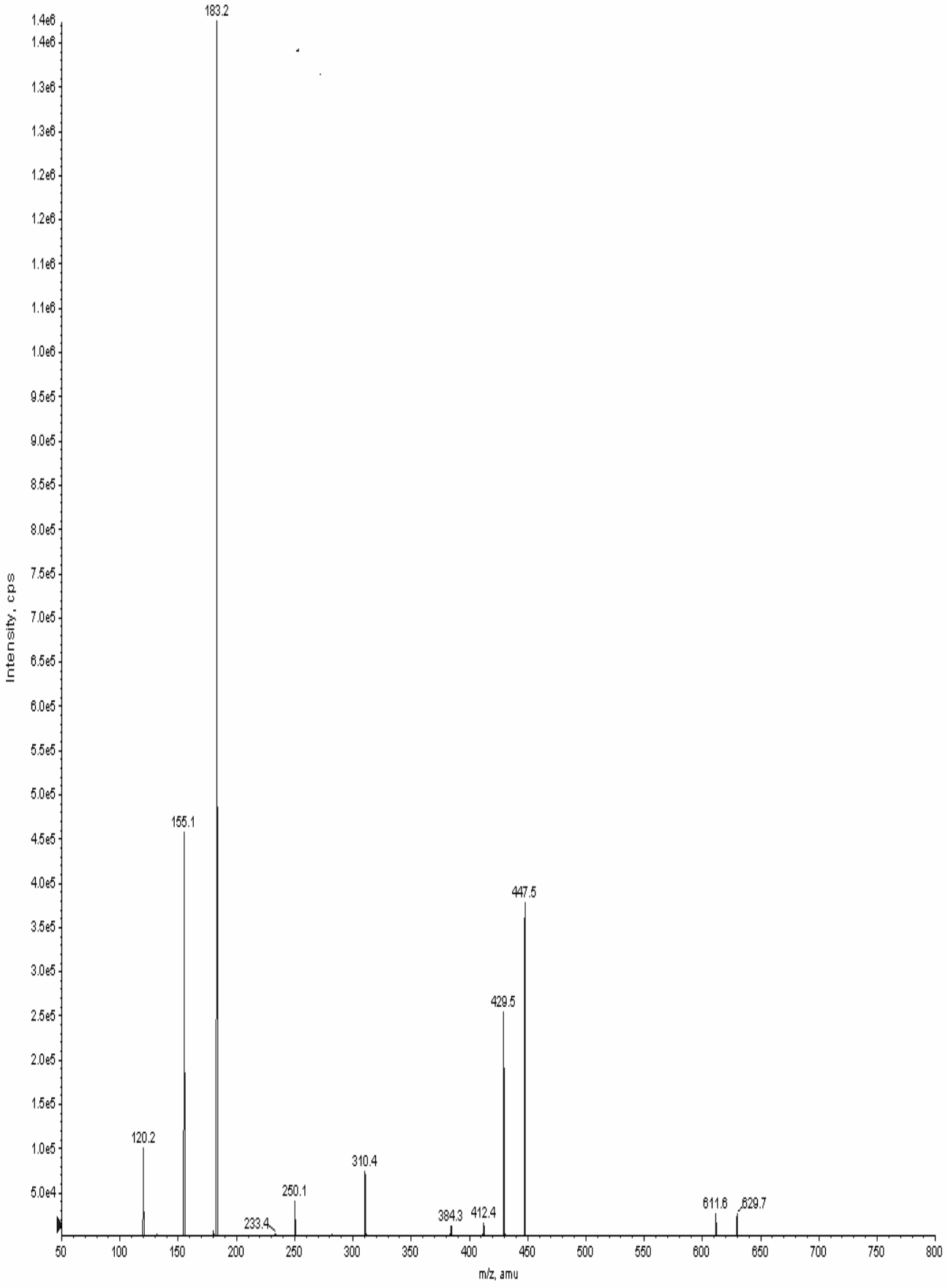

Figure 1. Mass spectra of lopinavir.

Molecular mass: $629.5 \mathrm{~m} / \mathrm{z}$ and fragment mass: $183.3 \mathrm{~m} / \mathrm{z}$ 


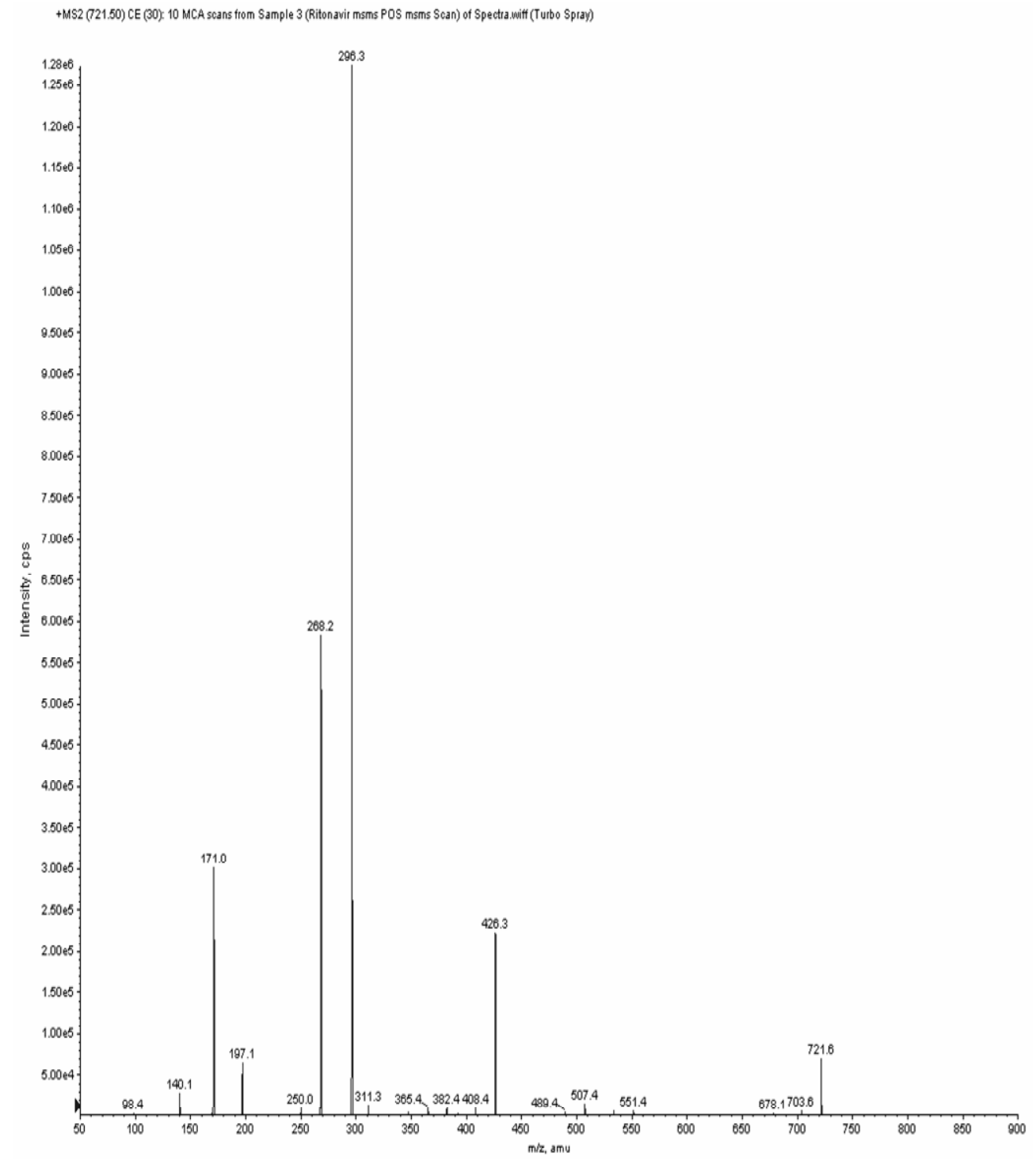

Figure 2. Mass spectra of ritonavir.

Molecular mass: $721.4 \mathrm{~m} / \mathrm{z}$ and fragment mass: $296.3 \mathrm{~m} / \mathrm{z}$

\section{Results and Discussion}

\section{Validation procedures}

Selectivity

Ten different sources of blank plasma samples were extracted and analysed for the assessment of potential interference with endogenous substances. The apparent response at the retention time of lopinavir and ritonavir was compared to the lower limit of quantification. Figure 3, 4, 5 and 6 shows representative chromatograms of selectivity for lopinavir and ritonavir. 


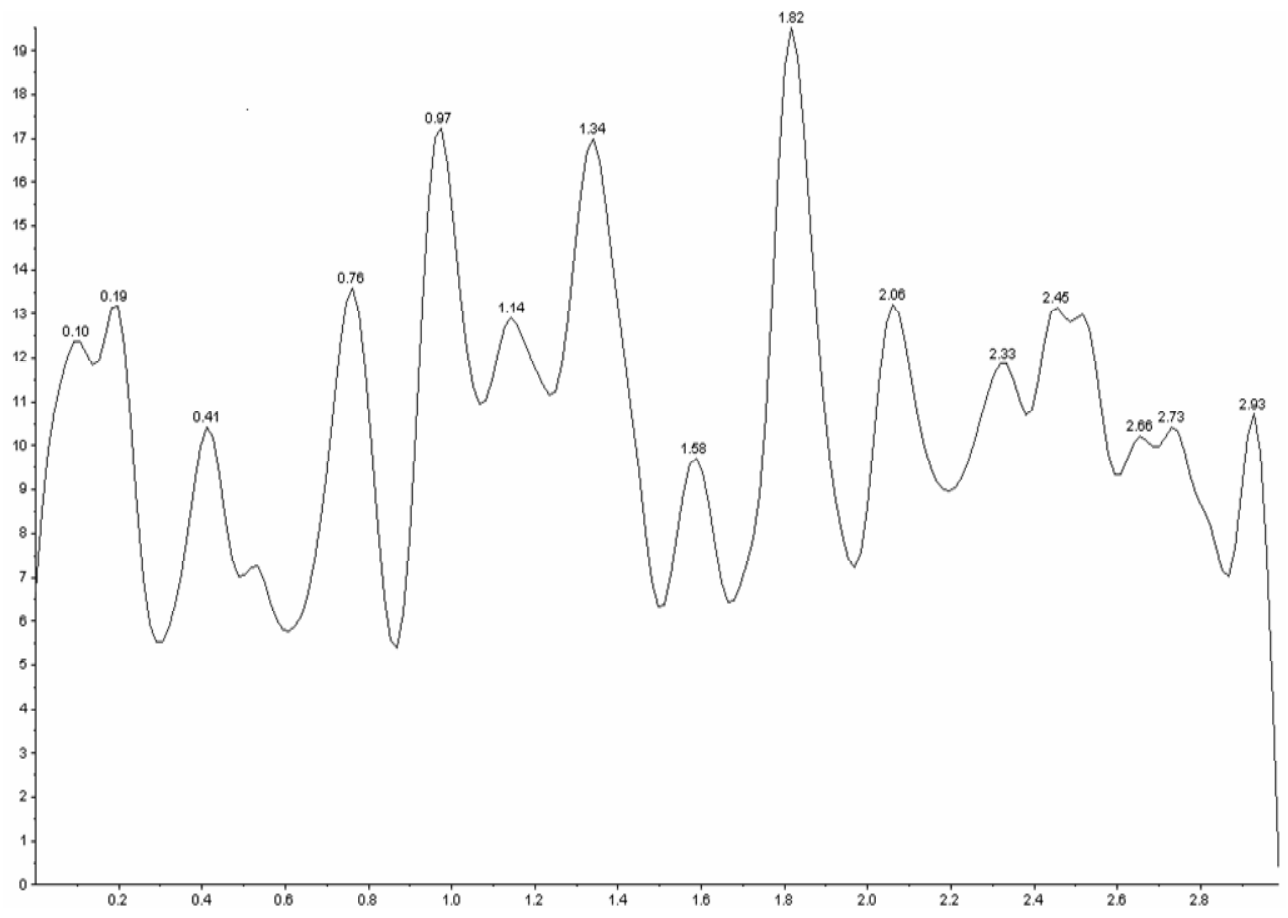

Figure 3. Representative chromatogram of plasma blank for lopinavir.

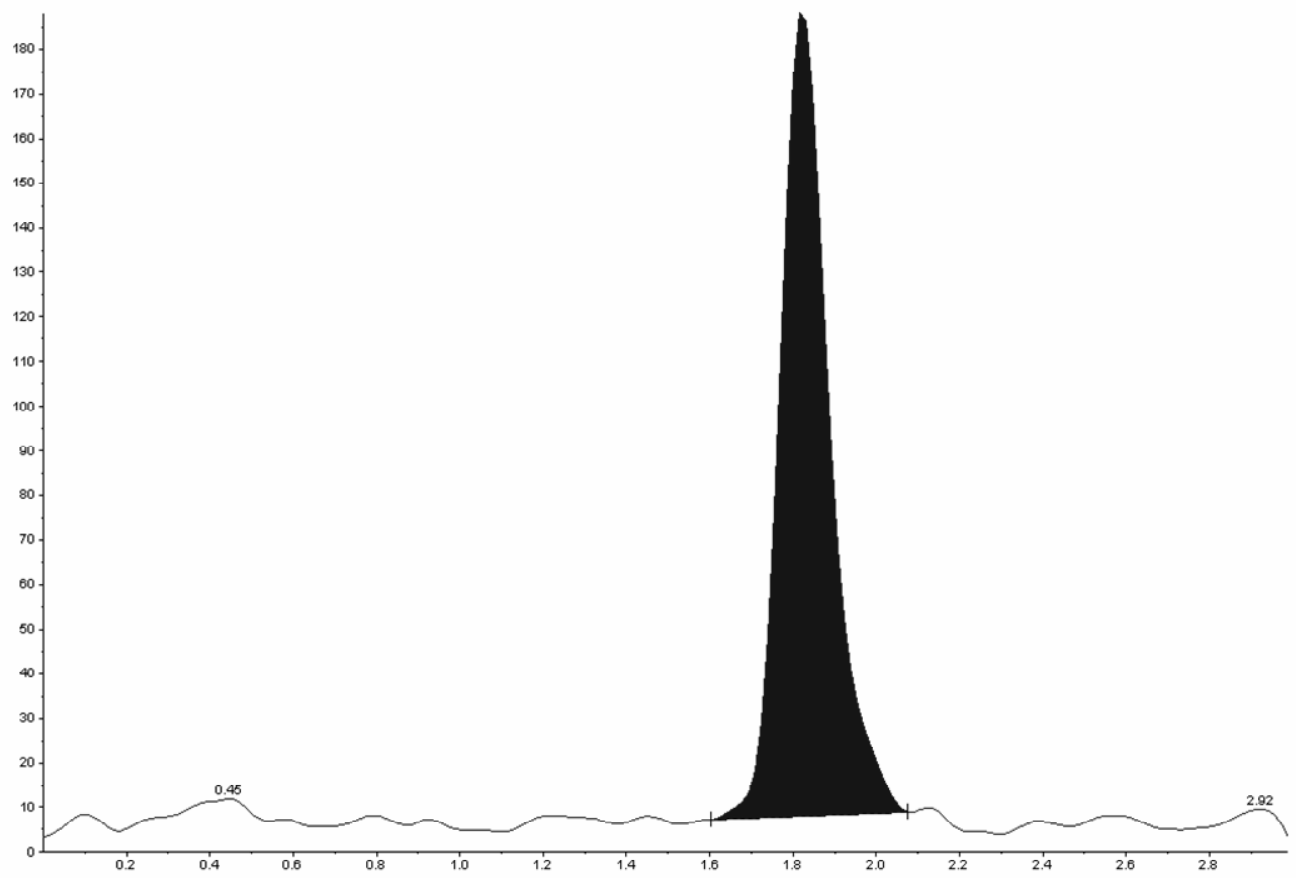

Figure 4. Representative chromatogram of plasma spiked with lopinavir at the lower limit of quantification $\left(50.0 \mathrm{ng} \mathrm{mL}^{-1}\right)$. 


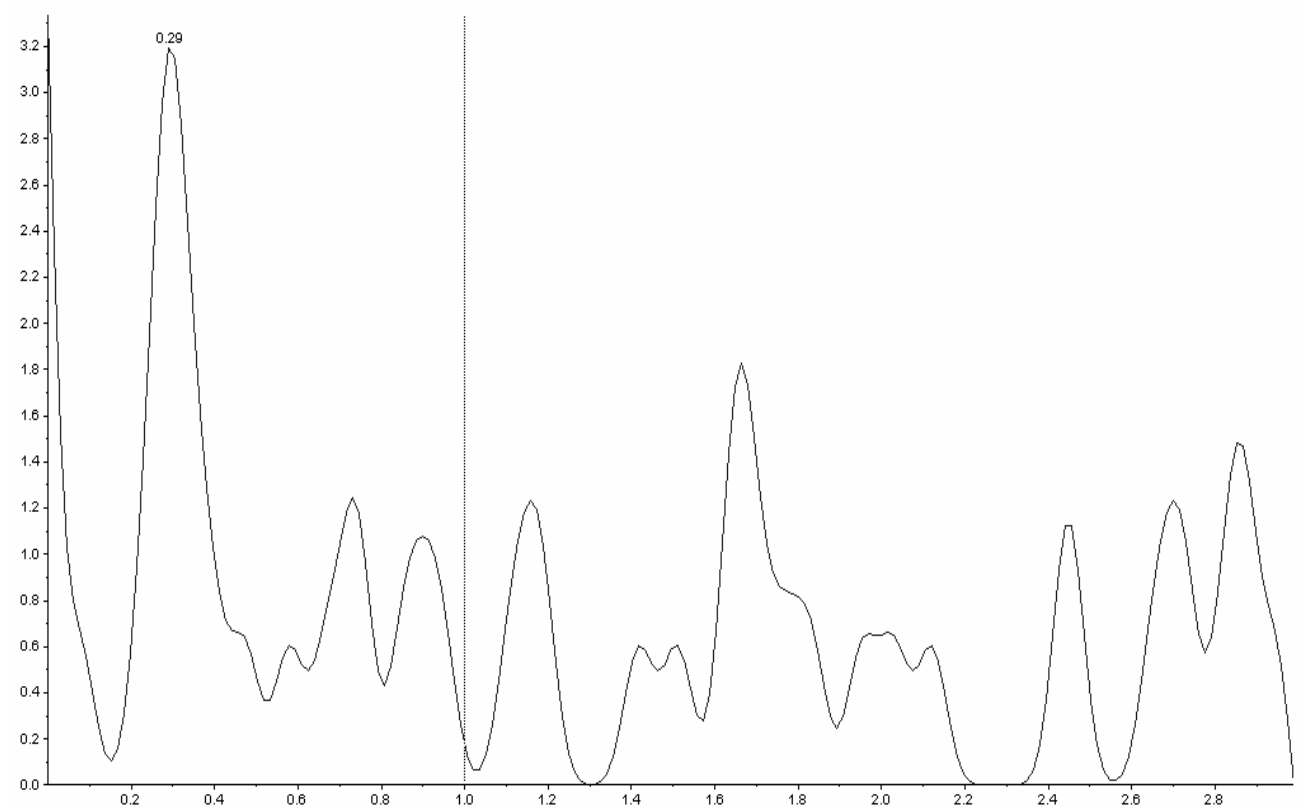

Figure 5. Representative chromatogram of plasma blank for ritonavir.

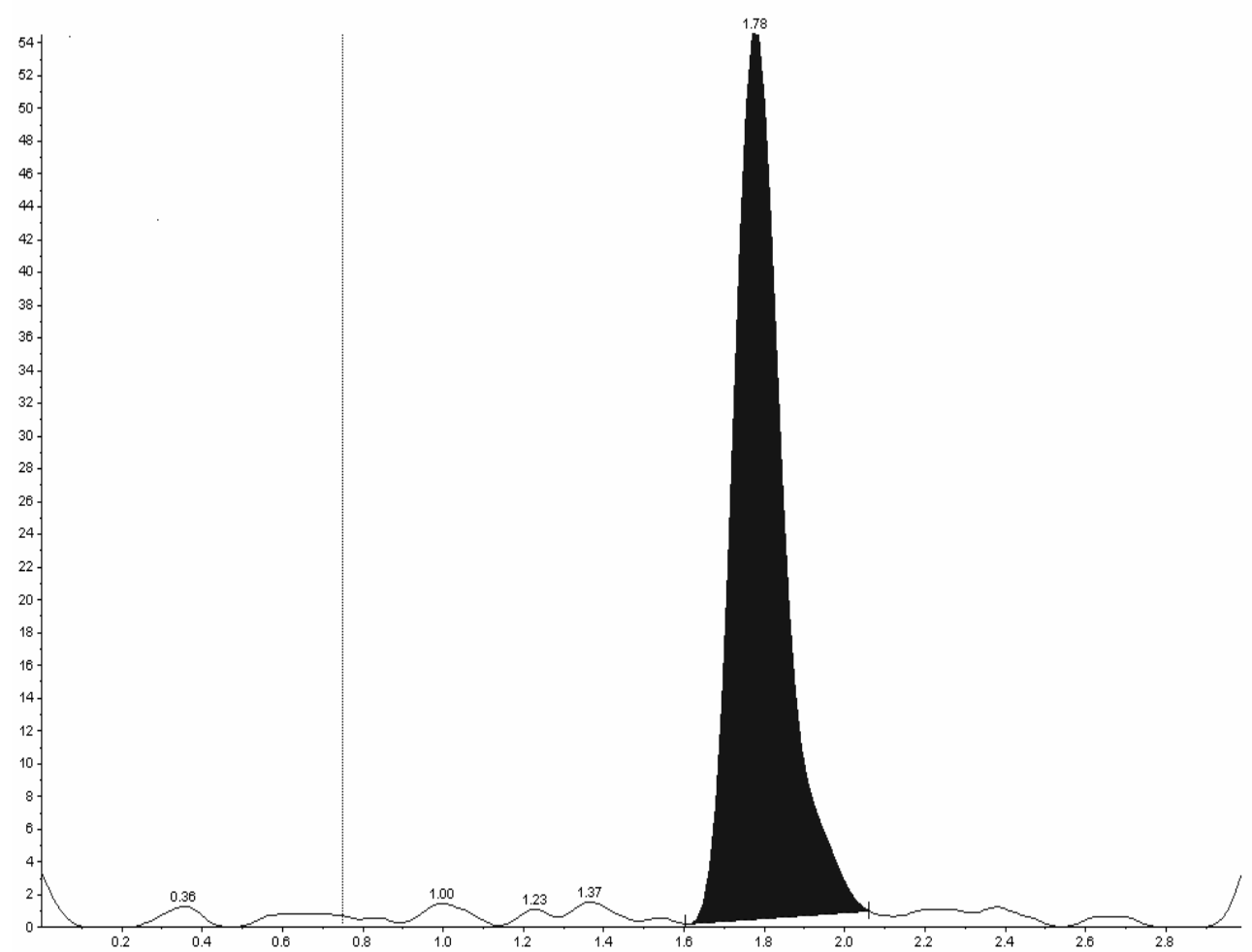

Figure 6. Representative chromatogram of plasma spiked with ritonavir at the lower limit of quantification $\left(20.0 \mathrm{ng} \mathrm{mL}^{-1}\right)$. 


\section{Linearity}

Linearity was studied over concentration of $50.000 \mathrm{ng} \mathrm{mL}^{-1}$ to $20000.000 \mathrm{ng} \mathrm{mL}^{-1}$ for lopinavir and $20.000 \mathrm{ng} \mathrm{mL}^{-1}$ to $3000.000 \mathrm{ng} \mathrm{mL}^{-1}$ for ritonavir. The calculation was done by linear weighted regression $\left(1 / \mathrm{X}^{2}\right)$.

\section{Accuracy and precision}

To validate the method for lopinavir and ritonavir, accuracy and precision were evaluated by analysis of three different concentration levels LQC (i.e. $150.0 \mathrm{ng} \mathrm{mL}^{-1}$ of lopinavir and $60.0 \mathrm{ng} \mathrm{mL}^{-1}$ of ritonavir), MQC (i.e. $8000.0 \mathrm{ng} \mathrm{mL}^{-1}$ of lopinavir and $800.0 \mathrm{ng} \mathrm{mL}^{-1}$ of ritonavir) and HQC (i.e. $18000.0 \mathrm{ng} \mathrm{mL}^{-1}$ of lopinavir and $2700.0 \mathrm{ng}$ $\mathrm{mL}^{-1}$ of ritonavir). The results obtained for precision and accuracy of lopinavir and ritonavir are listed in Table 2.

Table 1. Data of precision and accuracy.

\begin{tabular}{|c|c|c|c|c|c|c|}
\hline \multirow{4}{*}{$\begin{array}{l}\text { Nominal } \\
\text { Concentration in } \\
\text { ng mL } \mathrm{mL}^{-1}\end{array}$} & \multicolumn{3}{|c|}{ For lopinavir } & \multicolumn{3}{|c|}{ For ritonavir } \\
\hline & QC-1 & QC-2 & QC-3 & QC-1 & QC-2 & QC-3 \\
\hline & $(150.000)$ & $(8000.000)$ & $(18000.000)$ & $(60.000)$ & $(800.000)$ & $(2700.000)$ \\
\hline & $\begin{array}{c}\text { Observed } \\
\text { conc. }\end{array}$ & $\begin{array}{l}\text { Observed } \\
\text { conc. }\end{array}$ & $\begin{array}{l}\text { Observed } \\
\text { conc. }\end{array}$ & $\begin{array}{c}\text { Observed } \\
\text { conc. }\end{array}$ & $\begin{array}{c}\text { Observed } \\
\text { conc. }\end{array}$ & $\begin{array}{l}\text { Observed } \\
\text { conc. }\end{array}$ \\
\hline 1 & 168.237 & 7563.268 & 17988.243 & 65.813 & 766.547 & 2701.386 \\
\hline 2 & 138.184 & 7199.263 & 17869.587 & 59.996 & 729.562 & 2728.063 \\
\hline 3 & 154.859 & 8027.006 & 17165.230 & 60.028 & 825.382 & 2630.722 \\
\hline 4 & 159.090 & 8192.263 & 17172.471 & 70.583 & 807.584 & 2663.173 \\
\hline 5 & 158.252 & 8246.126 & 17126.408 & 60.311 & 813.105 & 2585.505 \\
\hline 6 & 145.301 & 8080.509 & 16656.402 & 53.271 & 784.695 & 2609.615 \\
\hline Mean & 153.987 & 7884.739 & 17329.724 & 61.667 & 787.813 & 2653.077 \\
\hline SD & 10.707 & 413.995 & 504.299 & 5.908 & 35.488 & 54.796 \\
\hline$\% \mathrm{CV}$ (Precision) & 6.95 & 5.25 & 2.91 & 9.58 & 4.50 & 2.07 \\
\hline$\%$ Accuracy & 102.66 & 98.56 & 96.28 & 102.78 & 98.48 & 98.26 \\
\hline
\end{tabular}

Recovery

For the recovery experiment, plasma extracted samples were prepared by spiking both lopinavir and ritonavir at three different concentrations levels (LQC, MQC, HQC) and extracted using extraction procedure. Recovery was carried out by comparing the area obtained from an extracted sample with standard (unextracted) sample. The results obtained for drug and internal standard recovery are listed in Table 2

\section{Stability}

The stock solution stability at room temperature for $24.0 \mathrm{~h}$ was compared with freshly prepared stock solution of lopinavir and ritonavir. Freeze thaw stability was done for LQC and HQC after three cycles at $-20^{\circ} \mathrm{C}$. Room temperature stability in plasma was done for $24 \mathrm{~h}$ at two concentrations LQC and HQC. Auto sampler stability was done for $24 \mathrm{~h}$ at two concentrations LQC and HQC.

Analyte and internal standard responded best to positive ionization using atmospheric turbo ion spray for ion production. In order to get higher response hypersil hypurity $\mathrm{C} 18$ $(4.6 \times 50 \mathrm{~mm})$ column was used. A number of different columns (Nucleosil, Nova pack, hypersil and Symmetry shield) were evaluated and hypersil hypurity C18 was found to give best chromatography with minimal matrix effects. 
Table 2. Extraction recovery of drug and internal standard.

\begin{tabular}{cccccccc}
\hline & \multicolumn{3}{c}{ For lopinavir } & \multicolumn{3}{c}{ For ritonavir } & $\begin{array}{c}\text { Internal } \\
\text { standard }\end{array}$ \\
\cline { 2 - 8 } $\begin{array}{c}\text { Nominal } \\
\text { concentration } \\
\text { in ng mL }\end{array}$ & $\begin{array}{c}\text { QC-1 } \\
(150.0)\end{array}$ & $\begin{array}{c}\text { QC-2 } \\
(8000.0)\end{array}$ & $\begin{array}{c}\text { QC-3 } \\
(18000.0)\end{array}$ & $\begin{array}{c}\text { QC-1 } \\
(60.0)\end{array}$ & $\begin{array}{c}\text { QC-2 } \\
(800.0)\end{array}$ & $\begin{array}{c}\text { QC-3 } \\
(2700.0)\end{array}$ & $5.0, \mu g \mathrm{~mL}^{-1}$ \\
\hline 1 & 84.71 & 89.14 & 94.36 & 87.67 & 91.02 & 97.45 & 96.43 \\
2 & 85.14 & 94.34 & 92.80 & 87.38 & 98.62 & 94.89 & 103.01 \\
3 & 94.60 & 93.43 & 93.17 & 102.00 & 98.19 & 94.00 & 104.37 \\
4 & 85.59 & 96.88 & 96.57 & 84.08 & 94.81 & 100.10 & 105.23 \\
5 & 89.73 & 90.38 & 91.17 & 93.52 & 93.16 & 90.03 & 100.73 \\
6 & 88.15 & 92.08 & 86.90 & 88.16 & 91.88 & 86.10 & 100.13 \\
Mean & 87.99 & 92.71 & 92.49 & 90.47 & 94.61 & 93.76 & 96.43 \\
SD & 3.780 & 2.801 & 3.278 & 6.417 & 3.205 & 5.055 & 103.01 \\
RSD & 4.30 & 3.02 & 3.54 & 7.09 & 3.39 & 5.39 & 104.37 \\
\hline
\end{tabular}

The assay was found to be linear in the concentration range 50.0 to $20000.0 \mathrm{ng} \mathrm{mL}^{-1}$ for lopinavir and 20.0 to $3000.0 \mathrm{ng} \mathrm{mL}^{-1}$ for ritonavir ( $\mathrm{r}>0.99$ ). Precision and accuracy were satisfactory at the three concentrations. Mean $\%$ recovery of the lopinavir and ritonavir was 91.06 and $92.95 \%$ respectively. Stability of analyte and internal standard stock solution in methanol was verified on storage for one month at $2-8^{\circ} \mathrm{C}$.

\section{Application of method}

The method can be successfully applied to determine concentration of drug in a bioequivalence study of lopinavir and ritonavir.

\section{Conclusion}

Rapid and sensitive LC-MS-MS method is reported for the simultaneous determination of lopinavir and ritonavir in human plasma. The Assay can be successfully applied to determine concentration of the drug in a bioequivalence study of lopinavir and ritonavir. The method allows high samples throughput due to short run time and relatively simple sample preparation procedure.

\section{References}

1. Product information, Kaletra Lopinavir/Ritonavir and Abbott Park, IL, Abbott Laboratories., 2000.

2. Adkins J C and Noble S, Drugs, 1998, 56, 1055-1064.

3. Corbett A. H, Lim M.L and Kashuba A D, Ann Pharmacother., 2002, 36, 1193-1203.

4. Marzolini C, Beguin A, Telenti A, Schreyer A, Buclin T, biollaz J and decosterd L. A, $J$ Chromatgr B, 2002, 774, 127-140.

5. Yoshico Usami and Tsuyoshi Oki, Chem Pharm Bull., 2003, 51(6), 715-718.

6. Ray J, Pang E and Carey D, J Chromatogr B Anal Technol Biomed Life Sci., 2002, 5, $775(2), 225-30$. 


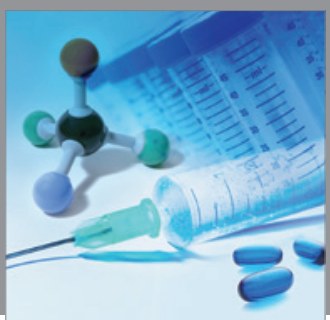

International Journal of

Medicinal Chemistry

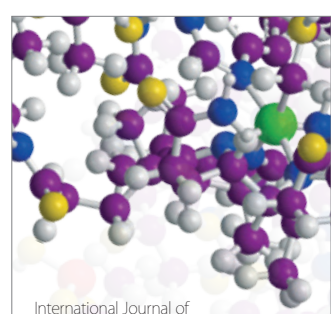

Carbohydrate Chemistry

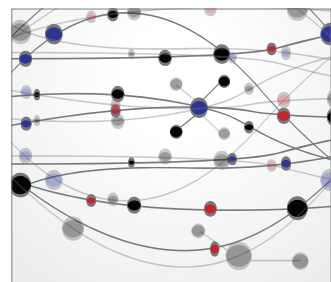

The Scientific World Journal
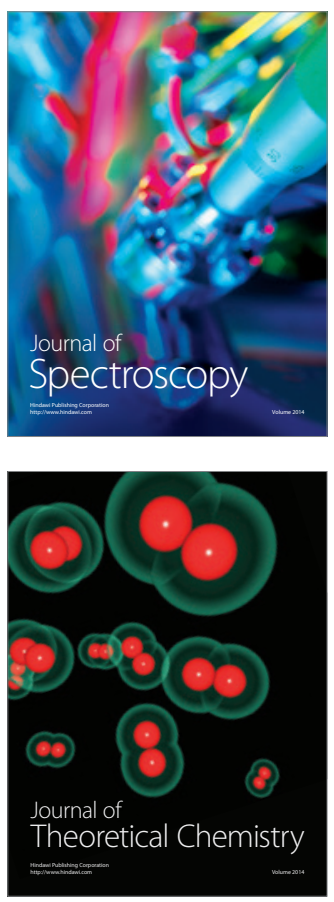
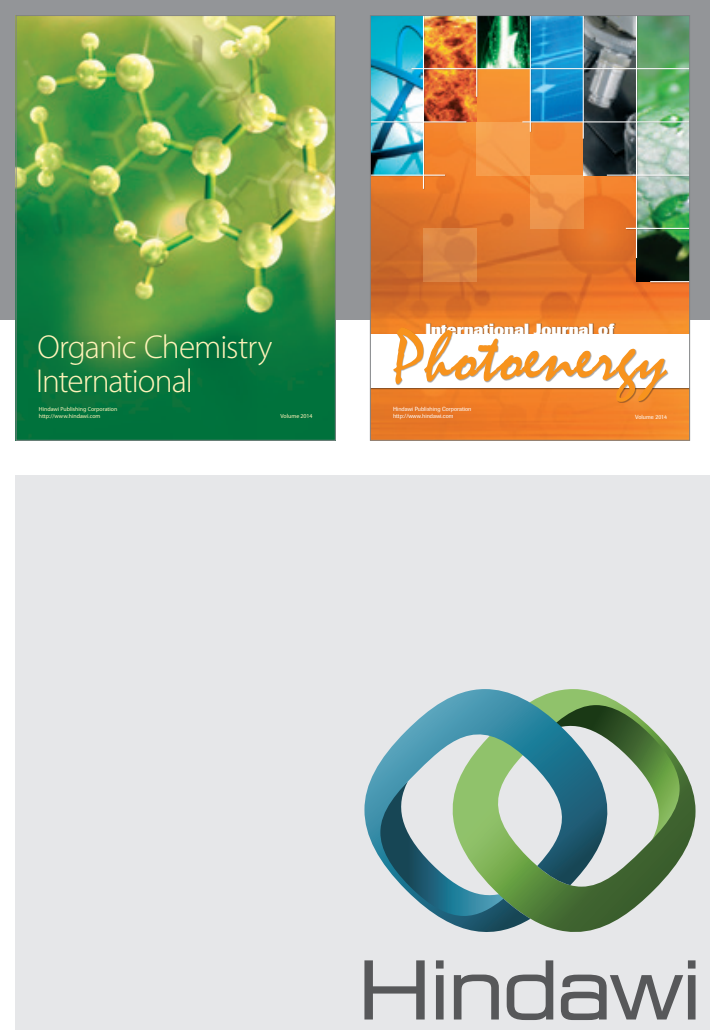

Submit your manuscripts at

http://www.hindawi.com
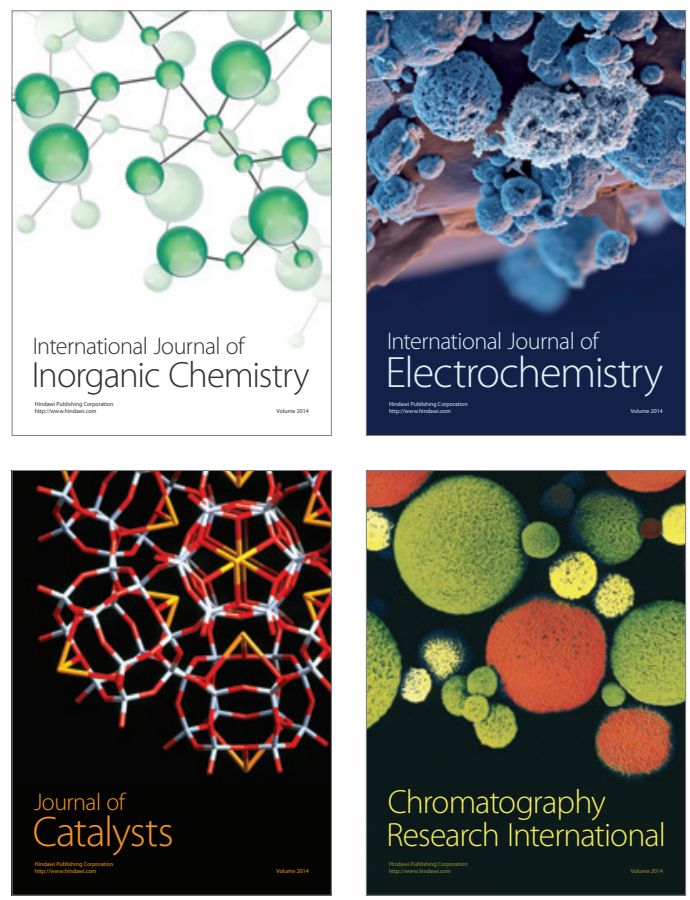
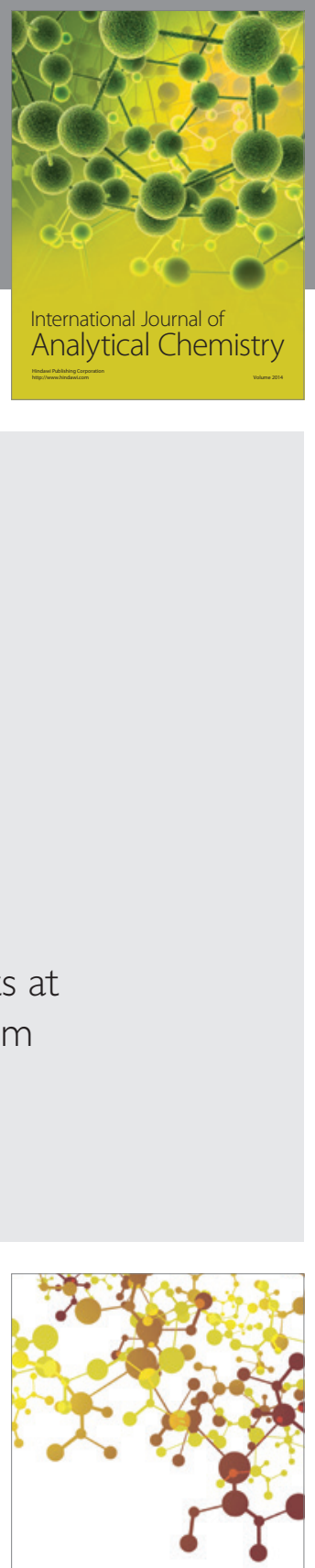

Journal of

Applied Chemistry
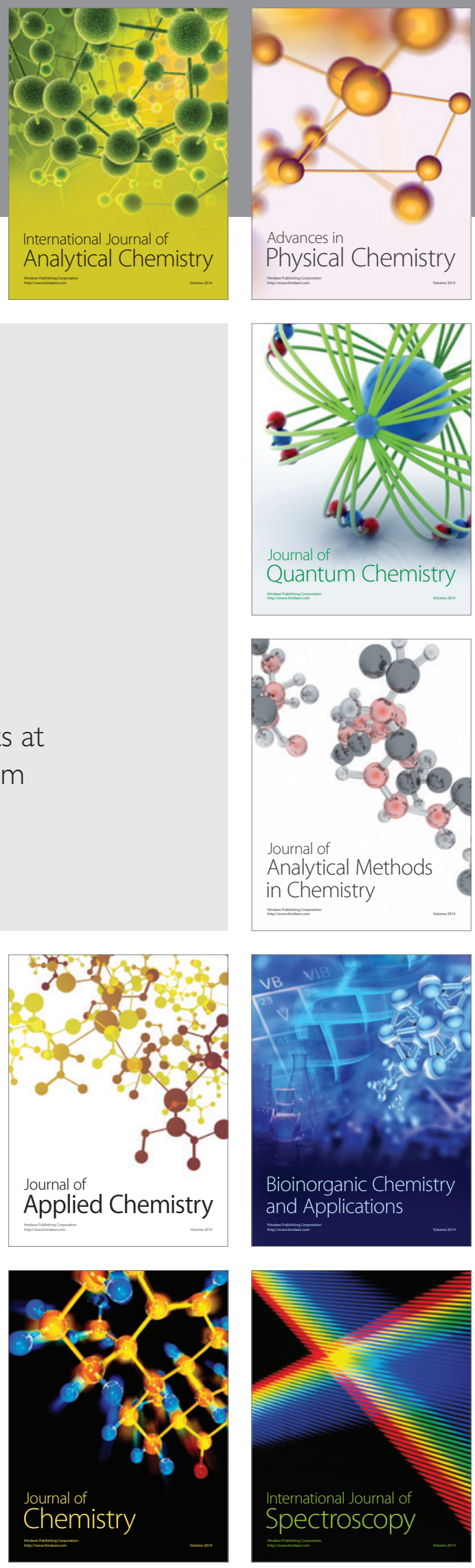